Supplement of The Cryosphere, 15, 3013-3019, 2021

https://doi.org/10.5194/tc-15-3013-2021-supplement

(C) Author(s) 2021. CC BY 4.0 License.

(c) (i)

Supplement of

\title{
Brief communication: Reduction in the future Greenland ice sheet surface melt with the help of solar geoengineering
}

Xavier Fettweis et al.

Correspondence to: Xavier Fettweis (xavier.fettweis@uliege.be)

The copyright of individual parts of the supplement might differ from the article licence. 


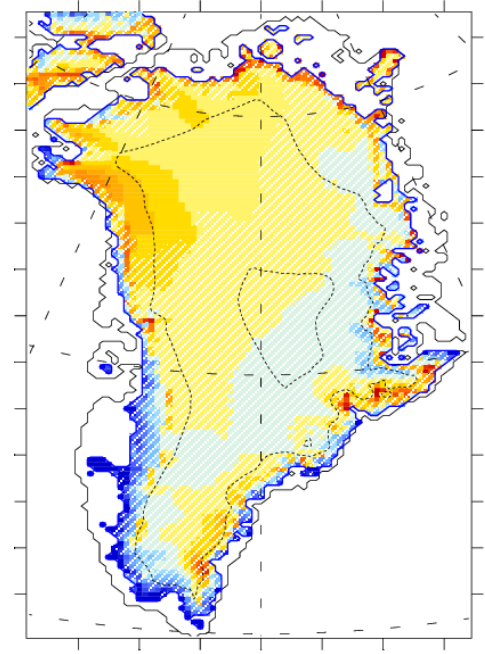

a) SMB anomaly (in $\mathrm{mmWE} / \mathrm{yr}$ )

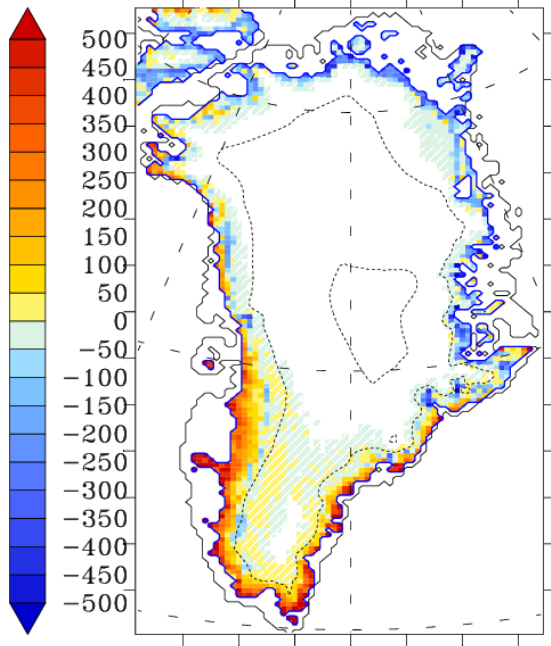

b) Runoff anomaly (in $\mathrm{mmWE} / \mathrm{yr}$ )
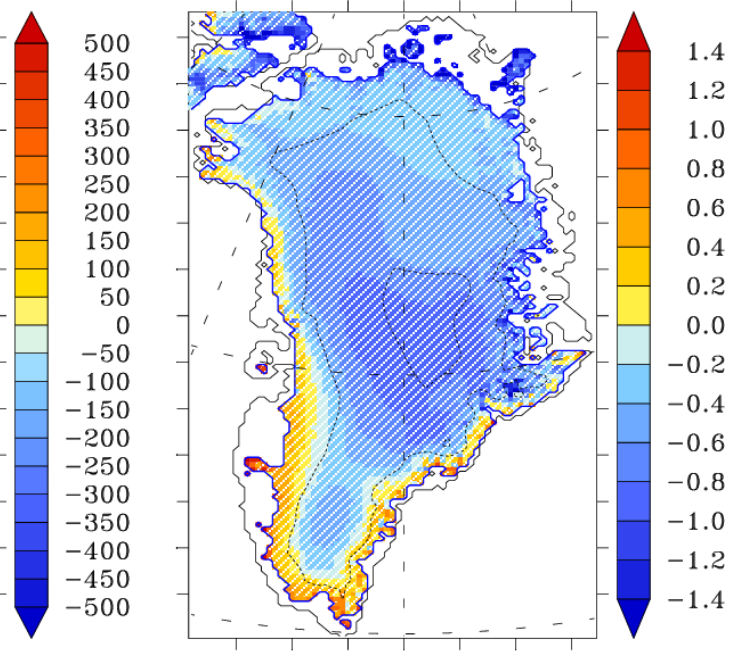

c) JJA $2 \mathrm{~m}$-temp. anomaly $\left(\right.$ in $\left.{ }^{\circ} \mathrm{C}\right)$

Fig. S1: a) Annual SMB (in mmWE/yr), b) meltwater runoff and c) summer $2 \mathrm{~m}$-temperature anomaly (in ${ }^{\circ} \mathrm{C}$ ) of $\mathrm{MAR}$ forced by CNRM-ESM2-1 vs MAR forced by ERA5 over 1981-2010. The anomalies lower than the 1981-2010 interannual variability are hatched and then considered as not statistically significant according to Fettweis et al. (2013 and 2017). The ice-sheet margins are represented by a blue line.

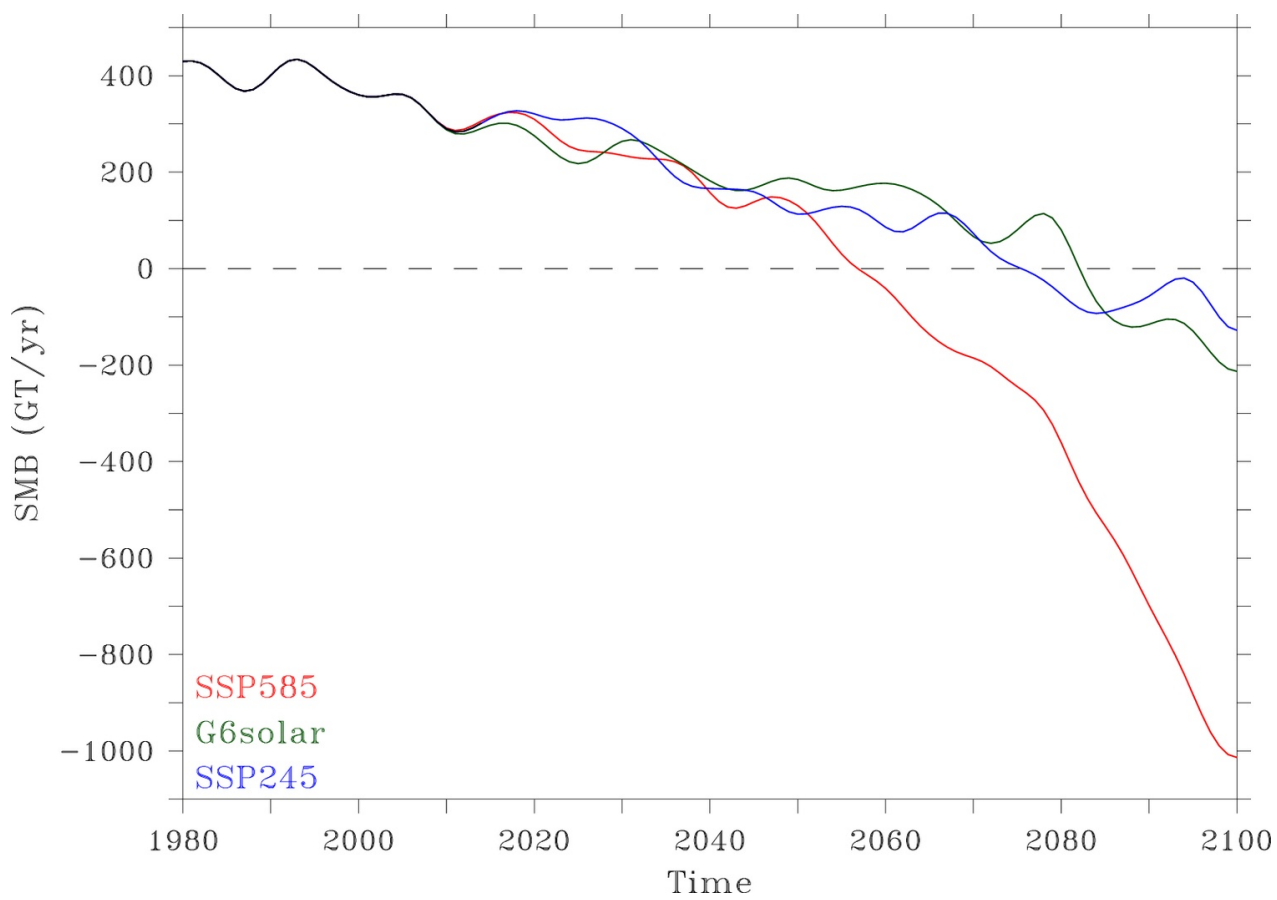

Fig. S2: Time series of the GrIS SMB in GT/yr (SMB anomalies are shown in Fig. 1b). 


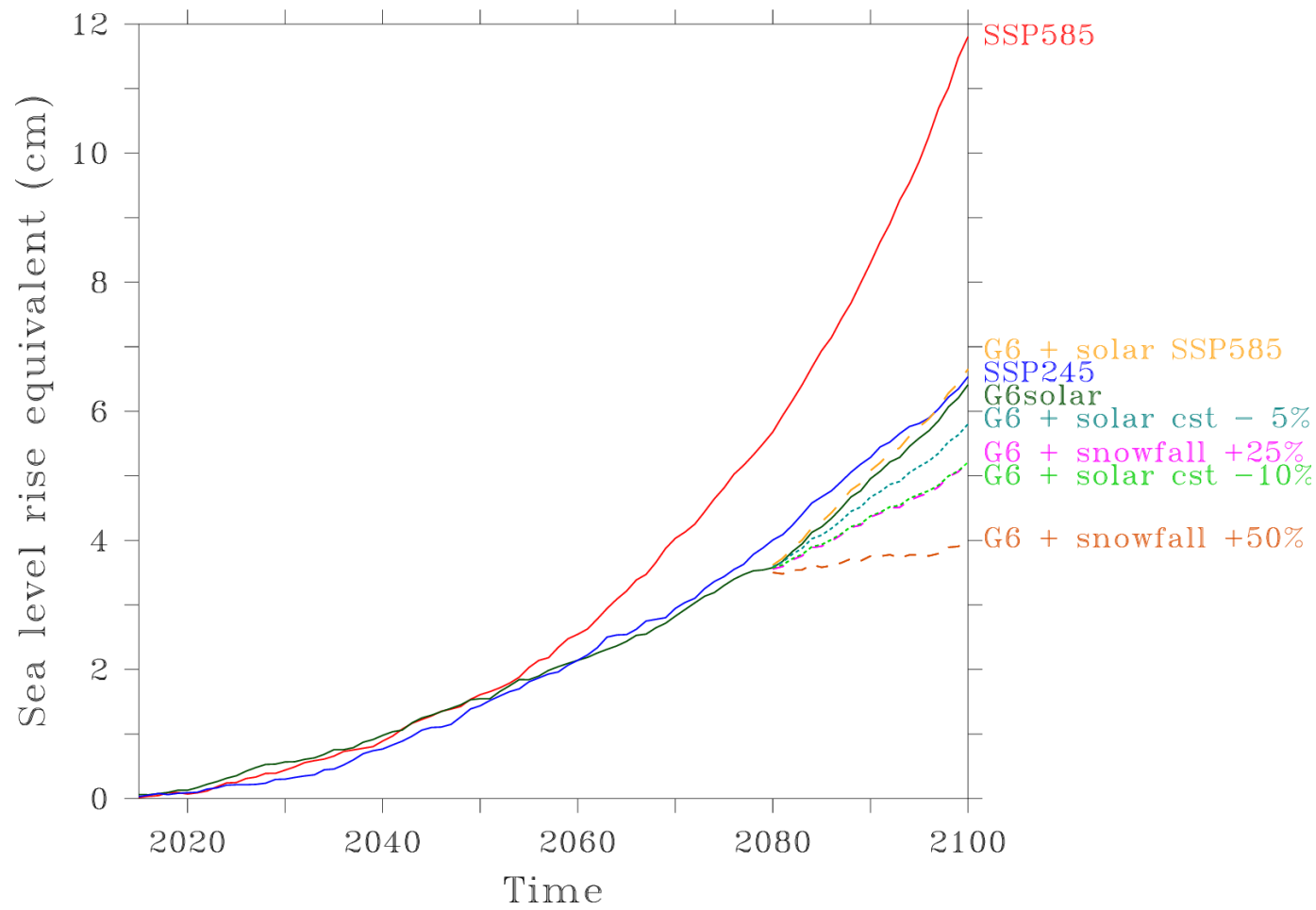

Fig. S3: Same as Fig 2 but from 2010.

\begin{tabular}{|l|c|c|c|c|c|c|}
\hline & $\begin{array}{c}\text { SMB } \\
(\mathrm{GT} / \mathrm{yr})\end{array}$ & Snowfall & Runoff & Meltwater & $\begin{array}{c}\text { JJA T2m } \\
\left({ }^{\circ} \mathrm{C}\right)\end{array}$ & $\begin{array}{c}\text { JJA SWD } \\
\left(\mathrm{W} / \mathrm{m}^{2}\right)\end{array}$ \\
\hline MAR_ERA5 & $369 \pm 101$ & $633 \pm 57$ & $293 \pm 83$ & $464 \pm 106$ & $-7.8 \pm 0.9$ & $282 \pm 6$ \\
\hline MAR_CNRM-ESM2 & $381 \pm 104$ & $650 \pm 66$ & $308 \pm 72$ & $452 \pm 95$ & $-8.3 \pm 0.8$ & $282 \pm 6$ \\
\hline
\end{tabular}

Table S1: Mean integrated values and standard deviation (i.e. the interannual variability) around this mean of SMB, snowfall, runoff, meltwater (in GT/yr) as well as mean summer (JJA) temperature (in ${ }^{\circ} \mathrm{C}$ ) and summer solar radiation (in $\mathrm{W} / \mathrm{m}^{2}$ ) as simulated by MAR forced by ERA5 and CNRM-ESM2-1 over 1981-2010.

\begin{tabular}{|l|l|}
\hline G6 + solar SSP585 & $\begin{array}{l}\text { G6solar with the "fixed" solar constant of SSP585 in the MAR radiative } \\
\text { scheme }\end{array}$ \\
\hline G6 + solar cst $-x \%$ & $\begin{array}{l}\text { G6solar with the solar constant of G6solar with an additionnal decrease of } x \\
\% \text { in the MAR radiative scheme }\end{array}$ \\
\hline G6 + snowfall $+x \%$ & $\begin{array}{l}\text { G6solar with the solar constant of G6solar with an artificial snowfall increase } \\
\text { of } x \% \text { as input of the MAR snow module }\end{array}$ \\
\hline
\end{tabular}

Table S2: List of the sensitivity experiments shown in Fig 2. 